\title{
Cell Wall Localization of Two DUF642 Proteins, BIIDXI and TEEBE, during Meloidogyne incognita Early Inoculation
}

\author{
Alexis Salazar-Iribe ${ }^{1}$, Esther Zúñiga-Sánchez ${ }^{2 *}$, Emma Zavaleta Mejía ${ }^{3}$, and Alicia Gamboa-deBuen ${ }^{1}$ \\ ${ }^{1}$ Instituto de Ecología, Universidad Nacional Autónoma de México. Avenida Universidad 3000, Ciudad Universitaria, \\ Delegación Coyoacán, Ciudad de México, C.P. 04510 \\ ${ }^{2}$ Facultad de Química, Universidad Nacional Autónoma de México, Avenida Universidad 3000, Ciudad Universitaria, \\ Delegación Coyoacán, Ciudad de México, C.P. 04510. Edificio E Laboratorio L-102 \\ ${ }^{3}$ Colegio de Postgraduados (CP), Instituto de Fitosanidad, km 35.5 Carr. México-Texcoco, Montecillo, Edo. de México \\ CP 56230
}

(Received on May 26, 2017; Revised on July 2, 2017; Accepted on July 20, 2017)

The root-knot nematode Meloidogyne incognita infects a variety of plants, including Arabidopsis thaliana. During migration, root-knot nematodes secrete different proteins to modify cell walls, which include pectolytic enzymes. However, the contribution of host cell wall proteins has not been described during this process. The function of two DUF642 cell wall proteins, BIIDXI (BDX, At4g32460) and TEEBE (TEB, At2g41800), in plant development could be related to the regulation of pectin methyl esterification status in the cell walls of different tissues. Accordingly, the expression of these two genes is up-regulated by auxin. BDX and TEB were highly induced during early $M$. incognita inoculation. Moreover, cell wall localization of the proteins was also induced. The cell wall localization of BDX and TEB DUF642 proteins during $M$. incognita early inoculation suggested that these two proteins could be involved in the regulation of the degree of pectin methylation during cell separation.

Keywords : Arabidopsis thaliana, DUF642 proteins, Meloidogyne incognita, plant cell wall

Handling Associate Editor : Sohn, Kee Hoon

\footnotetext{
*Corresponding author.

Phone) +55-56-22-52-76

E-mail) ezusa1120@hotmail.com

(c) This is an Open Access article distributed under the terms of the Creative Commons Attribution Non-Commercial License (http:// creativecommons.org/licenses/by-nc/4.0) which permits unrestricted noncommercial use, distribution, and reproduction in any medium, provided the original work is properly cited.
}

Articles can be freely viewed online at www.ppjonline.org.
The root-knot nematode Meloidogyne incognita infects a variety of plants, including Arabidopsis thaliana. The region of root elongation, close to the meristematic region, is the penetration zone for second stage juveniles (J2) that must migrate intercellularly to the root tip before they can enter the stele. Shortly after nematode infection, an important accumulation of auxin occurs (Grunewald et al., 2009a). During the infection process, nematodes manipulate the host auxin distribution network (Cabrera et al., 2014; Grunewald et al., 2009b). In the stele, rootknot juveniles stimulate the division of cells in the vascular parenchyma to form giant cells and ultimately, the feeding structure (Williamson and Hussey, 1996).

Plant cell wall structure is highly altered during $M$. incognita infection. During J2 migration, root-knot nematodes secrete cell wall degrading or modifying enzymes such as endoglucanases, pectato lyases (PL) and polygalacturonases (PG). These pectolytic enzymes, expressed in the glands in second-stage Meloidogyne juveniles, facilitate plant cell separation (Danchin et al., 2010; Wieczorek et al., 2014). Additionally, the activation of nematode genes encoding proteins involved in cell wall remodeling and degradation is observed at the early stages of infection (Shukla et al., 2017). After the initiation of feeding cells (stage 2), the expression of nematode genes encoding cell wall proteins is reduced, whereas the expression of cell wall related plant genes is induced to allow changes in cell wall structure for the formation of feeding cells. The contribution of host cell wall proteins has been described until the formation of the giant cells (Davis et al., 2004; Shukla et al., 2017; Wieczorek et al., 2014).

DUF642 is a highly conserved domain present in the 
DUF642 cell wall-related family of proteins that has been exclusively described in spermatophytes (Vázquez-Lobo et al., 2012). Transcriptomic analyses of $M$. incognita early infection (3 dpi) revealed an important induction of Atlg29980 expression, a DUF642 gene (Barcalá et al., 2010). Ten genes of this family are in the Arabidopsis thaliana genome, and the expression of BIIDXI ( $B D X$, At4g32460) and TEEBE (TEB, At2g41800) are highly induced by auxin in the different root zones (Salazar-Iribe et al., 2016; Zúñiga-Sánchez et al., 2014). In this study, we determined the effect of the inoculation of $M$. incognita juveniles on the expression and subcellular localization of BDX and TEB in roots from 5-d-old seedlings of A. thaliana. The same analysis was performed with the false rootknot nematode Nacobus aberrans, which also induces a specialized feeding site known as the syncytium; however, despite having a wide host range, this nematode has not been found infecting brassica crops such as broccoli and cabbage in Mexico and also can not complete its life cycle in the A. thaliana ecotype Columbia (unpublished data; E. Zavaleta, personal communication).

The transgenic plants PROBDX::GFP were transformed with a construction that include an $1983 \mathrm{bp}$ fragment upstream BDX ATG, PROTEB::GFP lines include an 890 bp fragment upstream of TEB ATG; at least three independent lines were analyzed showing the same expression pattern. These lines were used for expression analyses while for determination of subcellular localization PROBDX::BDXGFP and PROTEB::TEB-GFP lines (Salazar-Iribe et al., 2016; Zúñiga-Sánchez et al., 2014) were analyzed. The seeds from these transgenic plants and wt plants (col) were germinated after imbibition at $5^{\circ} \mathrm{C}$ for $2-3$ days and then grown vertically on petri dishes with $0.5 \mathrm{X}$ Murashige and Skoog (MS) basal medium containing $0.5 \%$ sucrose and $0.6 \%$ agar. Seed germination was conducted in a CONVIRON growth chamber under long-day conditions at 20-22 ${ }^{\circ} \mathrm{C}$.

Second stage juveniles (J2s) of the root-knot nematodes $M$. incognita and $N$. aberrans were obtained from egg masses extracted from Capsicum annum and Solanum lycopersicum roots, respectively. Grown as described previously, 7-d-old seedlings were inoculated with $250 \mathrm{~J} 2 \mathrm{~s}$ of $M$. incognita or $N$. aberrans per plant. DR5::GFP transgenic plants were used for the control of the inoculation. As a negative control, the solution preserving nematodes was used for plant infection; the solution was centrifuged at low speed and the supernatant without nematodes was used for the inoculation. Both transgenic and wt plants were inoculated under the same conditions.

GFP was imaged at $485-545 \mathrm{~nm}$ with an Olympus. To- kyo, Japan. Images of plant tissues without internal fluorescence were used as controls. Images were assembled using Photoshop version 5.0 (California, USA.).

Visualization of the auxin responsive reporter DR5::GFP (Fig. 1A) was evident at two days after inoculation with J2s of M. incognita (Fig. 1B). Auxin was in all types of cells of the M. incognita inoculated roots (Fig. 1B), but no change in auxin pattern was detected in plants inoculated with $N$. aberrans (Fig. 1C). In three independent experiments, an important increase was detected in expression of both $B D X$ and TEB (Fig. 1E, H) compared with non-inoculated roots (Fig. 1D, G). Changes in cell type expression pattern were also promoted by nematode inoculation. For $B D X$, a strong GFP fluorescence was observed only in the vascular tissue of the control roots (Fig. 1D), whereas the fluorescence was highly detected in other cell types of the infected roots (Fig. 1E). In A. thaliana plants inoculated with $N$. aberrans, a slight induction of auxin (Fig. 1C) or expression of $B D X$ (Fig. 1F) and TEB (Fig. 1I) was observed at 2 days after inoculation. BDX and TEB proteins have been detected in cell wall proteomes from different plant tissues, including cell suspension cultures (Jamet et al., 2006). Cell wall localization of these two proteins in epidermal cells from primary roots treated with auxin has also been described (Salazar-Iribe et al., 2016). In non-treated roots, BDX was located intracellularly in cortex and endodermic cells (Fig. 2A). Meloidogyne incognita inoculation promoted BDX localization to cell walls in different cell types (Fig. 2B). For TEB, no fluorescence was detected in control roots but was localized in the cell walls in different cell types of inoculated roots (Fig. 2C, D).

The accumulation and redistribution of auxin during root-knot nematode inoculation are processes directly involved with plant susceptibility to infection (Kyndt et al., 2016). An important increase in auxin was detected in the roots of the seedlings inoculated with $M$. incognita, whereas almost no increase in auxin was observed for $N$. aberrans inoculation (Fig. 1). This absence of increase in auxin is consistent with previous observations that $A$. thaliana is not susceptible to $N$. aberrans infection. Additionally, a differential regulation in the expression of plant cell wall-related genes between susceptible and resistant $S$. lycorpersicum to $M$. incognita infection has been described (Shukla et al., 2017). The up-regulation of $B D X$ and $T E B$ promoters observed in roots during $M$. incognita juvenile migration suggested a potential transcriptional regulation of the expression of these genes upon nematode compatible infection (Fig. 1). By contrast, no changes in TEB and $B D X$ expression were observed during $N$. aberrans inoculation; this response is similar to that described in resistant $S$. $l y$ - 


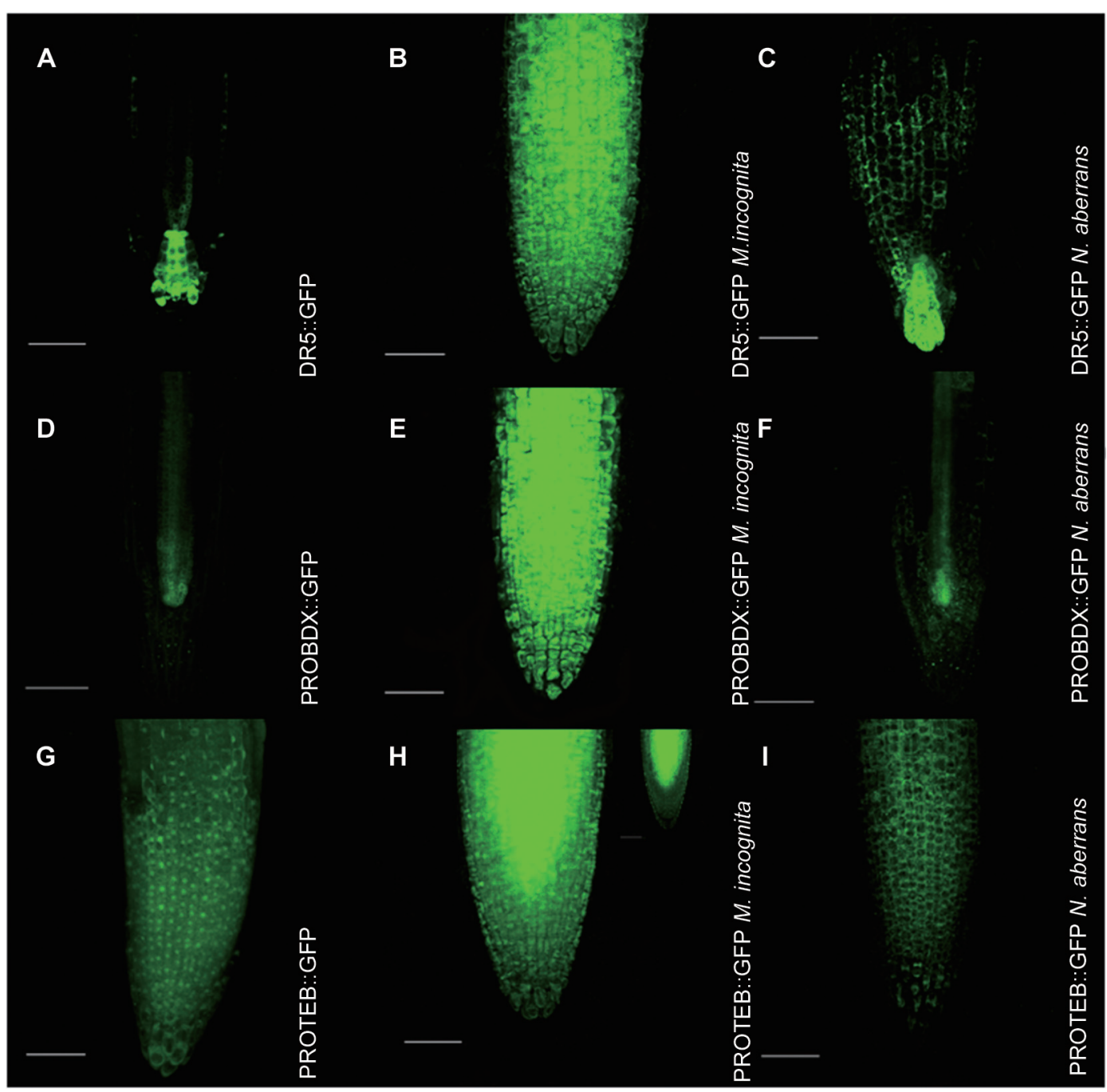

Fig. 1. $B D X$ and TEB expression is highly induced by $M$. incognita early inoculation. 5-d-old seedlings of DR5::GFP (A-C), PROBDX::GFP (D-F) and PROTEB::GFP (G-I) transgenic plants were used as controls and inoculated with J2 M. incognita and N. aberrans. For $B D X$ expression, GFP was detected in the pro-vascular tissue of the meristematic zone in primary roots (D), and GFP was detected in all cell types of the meristematic and transition zone in primary roots in seedlings inoculated with M. incognita (2 dpi) (E). PROBDX::GFP in the pro-vascular tissue of the meristematic zone in primary roots of seedlings inoculated with $N$. aberrans (2 dpi) (F). PROTEB::GFP in the epidermic cells of the meristematic zone in primary roots (G). PROTEB::GFP in all cell types of the meristematic and transition zone in primary roots of seedlings inoculated with $M$. incognita (2 dpi) (H). PROTEB::GFP in the epidermic cells of the meristematic zone in primary roots of seedlings inoculated with $N$. aberrans ( 2 dpi) (I). Scale bars $=100 \mu$ m. All the images are projections of confocal Z-stacks.

corpersicum in which no significant alteration is observed in the expression of genes involved in the modulation of cell wall architecture (Shukla et al., 2017).

The relevance of cell wall-modifying enzymes as phytonematode effectors that aid in nematode invasion and migration into and within hosts has been extensively documented in different plants (Ibrahim et al., 2011; Shivakumara et al., 2017). The pectolytic enzymes secreted by the nematode are involved in cell separation by promoting the degradation of the middle lamella, which is the pectin layer that fills the space between adjacent cells. However, no role of plant cell wall proteins has been described during this process. The promotion of the expression and cell wall localization of BDX and TEB by $M$. incognita J2 inoculation suggests that the early plant-pathogen interaction also involves the induction of plant proteins that participate in cell wall remodeling. These results also suggest that host plant cell wall proteins are involved in the cellular separa- 

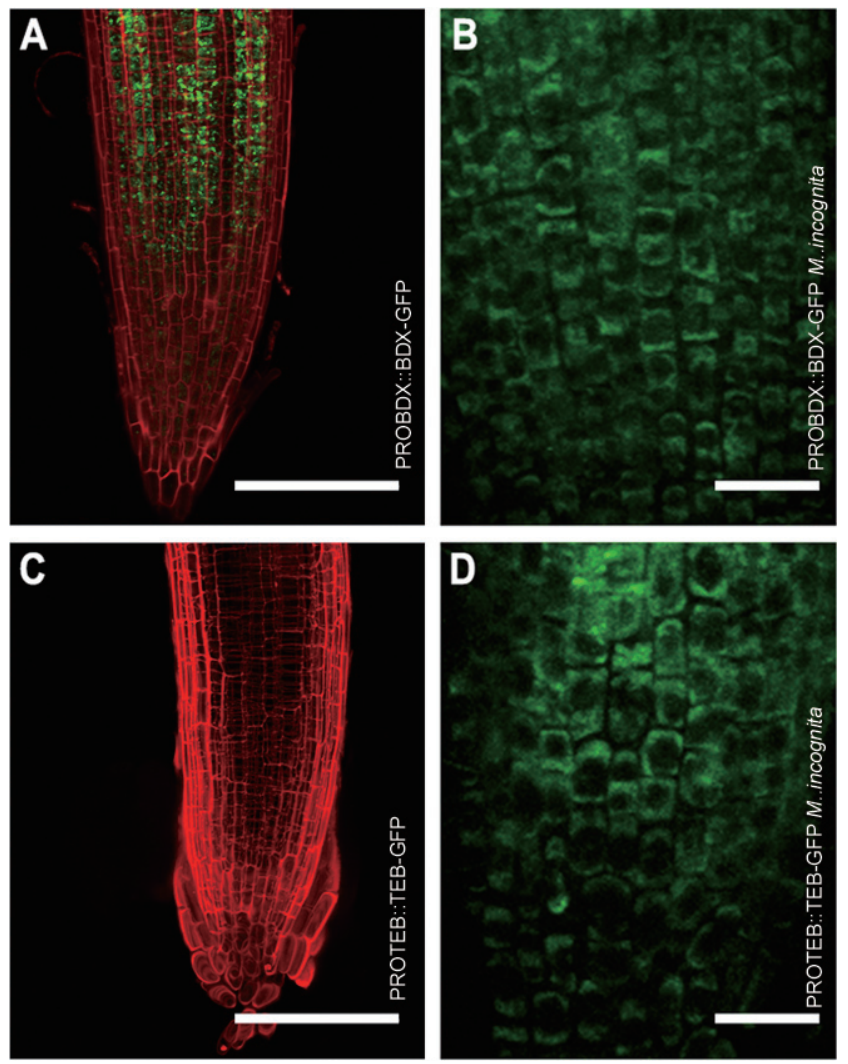

Fig. 2. Cell wall localization of BDX and TEB was detected in plants inoculated with $M$. incognita. 5-d-old seedlings of PROBDX::BDX-GFP (A-B) and PROTEB::TEB-GFP (C-D) transgenic plants were used and inoculated with $\mathrm{J} 2 \mathrm{M}$. incognita. Meristematic zone of primary root from control PROBDX::BDXGFP seedlings (A); GFP was detected intracellularly. Meristematic zone of primary root from inoculated PROBDX::BDXGFP seedlings (B); GFP was detected in the cell walls of the epidermal cells. Meristematic zone of primary root from control PROTEB::TEB-GFP seedlings (C); GFP was not detected. Meristematic zone of primary root from PROTEB::TEB-GFP seedlings (D); GFP was detected in the cell walls of epidermal cells. A and C scale bars $=100 \mu \mathrm{m} ; \mathrm{B}$ and D scale bars $=20 \mu \mathrm{m}$. A and $\mathrm{C}$ images are projections of confocal Z-stacks.

tion for the intercellular migration of $\mathrm{J} 2 \mathrm{~s}$. Plant cells are firmly adhered to one another by the middle lamellae, and the degradation of the low methylated pectin by PGs and PLs promotes cell separation. Pectinesterases or PMEs and the regulators are involved in maintaining a low degree of pectin methylesterification. The role of DUF642 proteins in pectin methyl esterase regulation has been described in A. thaliana (BDX and TEB), Vitis quinquangularis (VqDUF642) and Amaranthus hypochondriacus (AhDGR2). An increase in PME activity in leaves from overexpressed VqDUF642 A. thaliana plants has been described, with the conclusion that VqDUF642 is involved in plant development and defense against pathogenic infections (Xie and Wang, 2016). The cell wall localization of BDX and TEB DUF642 proteins during $M$. incognita inoculation suggested that these two proteins could be involved in the regulation of the degree of pectin methylation during cell separation, as was previously described during testa rupture (Zúñiga-Sánchez et al., 2014).

\section{Acknowledgments}

We thank Dra. Karina Jiménez Durán for the Confocal studies. The Programa de Apoyo a Proyectos de Investigación e Innovación Tecnológica (PAPIIT) grant IN207915 (Universidad Nacional Autónoma de México) and Consejo Nacional de Ciencia y Tecnología (CONACyT) grant 155074 supported this work. ASI is a $\mathrm{PhD}$ student (Posgrado en Ciencias Biológicas, UNAM) and received a CONACyT fellowship.

\section{References}

Barcalá, M., García, A., Cabrera, J., Casson, S., Lindsey, K., Favery, B., García-Casado, G., Solano, R., Fenoll, C. and Escobar, C. 2010. Early transcriptomic events in microdissected Arabidopsis nematode-induced giant cells. Plant J. 61:698712 .

Cabrera, J., Barcala, M., Fenoll, C. and Escobar, C. 2014. Transcriptomic signatures of transfer cells in early developing nematode feeding cells of Arabidopsis focused on auxin and ethylene signaling. Front. Plant Sci. 5:107.

Davis, E. L., Hussey, R. S. and Baum, T. J. 2004. Getting to the roots of parasitism by nematodes. Trends Parasitol. 20:134141.

Danchin, E. G., Rosso, M. N., Vieira, P., de Almeida-Engler, J., Coutinho, P. M., Henrissat, B. and Abad, P. 2010. Multiple lateral gene transfers and duplications have promoted plant parasitism ability in nematodes. Proc. Natl. Acad. Sci. U.S.A. 107:17651-17656.

Grunewald, W., Van Noorden, G., Van Isterdael, G., Beeckman, T., Gheysen, G. and Mathesius, U. 2009a. Manipulation of auxin transport in plant roots during Rhizobium symbiosis and nematode parasitism. Plant Cell 21:2553-2562.

Grunewald, W., Cannoot, B., Friml, J. and Gheysen, G. 2009b. Parasitic nematodes modulate PIN-mediated auxin transport to facilitate infection. PLoS Pathog. 5:e1000266.

Ibrahim, H. M., Hosseini, P., Alkharouf, N. W., Hussein, E. H., Abd El Kader, Y., Aly, M. A. and Matthews, B. F. 2011. Analysis of gene expression in soybean (Glycine max) roots in response to the root knot nematode Meloidogyne incognita using microarrays and KEGG pathways. BMC Genomic. $12: 220$ 
Jamet, E., Canut, H., Boudart, G. and Pont-Lezica, R. F. 2006. Cell wall proteins: a new insight through proteomics. Trends Plant Sci. 11:33-39.

Kyndt, T., Goverse, A., Haegeman, A., Warmerdam, S., Cecilia Wanjau, C., Mona Jahani, M., Gilbert Engler, G., Janice de Almeida Engler, J. and Gheysen, G. 2016. Redirection of auxin flow in Arabidopsis thaliana roots after infection by root-knot nematodes. J. Exp. Bot. 67:4559-4570.

Shivakumara, T. N., Chaudhary, S., Kamaraju, D., Dutta, T. K., Papolu, P. K., Banakar, P., Sreevathsa, R., Singh, B., Manjaiah, K. M. and Rao, U. 2017. Host-induced silencing of two pharyngeal gland genes conferred transcriptional alteration of cell wall-modifying enzymes of Meloidogyne incognita vis$\grave{a}$-vis perturbed nematode infectivity in eggplant. Front. Plant Sci. 8:473.

Shukla, N., Yadav, R., Kaur, P., Rasmussen, S., Goel, S., Agarwal, M., Jagannath, A., Gupta, R. and Kumar, A. 2017. Transcriptome analysis of root-knot nematode (Meloidogyne incognita)-infected tomato (Solanum lycopersicum) roots reveals complex gene expression profiles and metabolic networks of both host and nematode during susceptible and resistance responses. Mol. Plant Pathol. doi: 10.1111/ mpp.12547 (in press).

Salazar-Iribe, A., Agredano-Moreno, L. T., Zúñiga-Sánchez, E.,
Jiménez-Garcia, L. F. and Gamboa-deBuen, A. 2016. The cell wall DUF642 At2g41800 (TEB) protein is involved in hypocotyl cell elongation. Plant Sci. 253:206-214.

Vázquez-Lobo, A., Roujol, D., Zúñiga-Sánchez, E., Piñero, D., Albenne, C., Gamboa-de Buen, A. and Jamet, E. 2012. The highly conserved spermatophyte cell wall DUF642 protein family: phylogeny and first evidence of interaction with cell wall polysaccharides in vitro. Mol. Phylogenet. Evol. 63:510520.

Wieczorek, K., Elashry, A. E. N., Quentin, M., Grundler, F. M., Favery, B., Seifert, G. J. and Bohlmann, H. 2014. A distinct role of pectate lyases in the formation of feeding structures induced by cyst and root-knot nematodes. Mol. Plant-Microbe Interact. 27:901-912.

Williamson, V. M. and Hussey, R. S. 1996. Nematode pathogenesis and resistance in plants. Plant Cell 8:1735-1745.

Xie, X. and Wang, Y. 2016. VqDUF642, a gene isolated from the Chinese grape Vitis quinquangularis, is involved in berry development and pathogen resistance. Planta 244:1075-1094.

Zúñiga-Sánchez, E., Soriano, D., Martínez-Barajas, E., OrozcoSegovia, A. and Gamboa-deBuen, A. 2014. BIIDXI, the At4g32460 DUF642 gene, is involved in pectin methyl esterase regulation during Arabidopsis thaliana seed germination and plant development. BMC Plant Biol. 14:338. 